\title{
Genetic correlations of milk fatty acid contents predicted from milk mid-infrared spectra in New Zealand dairy cattle
}

\author{
N. Lopez-Villalobos, ${ }^{1 *} \oplus$ R. J. Spelman, ${ }^{2}{ }$ J. Melis, ${ }^{2}$ S. R. Davis, ${ }^{2}{ }^{\oplus}$ S. D. Berry, ${ }^{3} \oplus$ K. Lehnert, ${ }^{3}$ \\ N. W. Sneddon, ${ }^{1,4} \odot$ S. E. Holroyd, ${ }^{4}$ A. K. MacGibbon, ${ }^{4} \oplus$ and R. G. Snell ${ }^{3}$ \\ ${ }^{1}$ School of Agriculture and Environment, Massey University, Private Bag 11-222, Palmerston North 4442, New Zealand \\ ${ }^{2}$ Livestock Improvement Corporation, Private Bag 3016, Hamilton 3240, New Zealand \\ ${ }^{3}$ School of Biological Sciences, The University of Auckland, Private Bag 92019, Auckland 1142, New Zealand \\ ${ }^{4}$ Fonterra Research and Development Centre, Palmerston North 4442, New Zealand
}

\section{ABSTRACT}

The objective of this study was to estimate genetic correlations among milk fatty acid (FA) concentrations in New Zealand dairy cattle. Concentrations of each of the most common FA, expressed as a percentage of the total FA, were determined by gas chromatography on a specific cohort of animals. Using this data set, prediction equations were derived using mid-infrared (MIR) spectroscopy data collected from the same samples. These prediction equations were applied to a large data set of MIR measurements in 34,141 milk samples from 3,445 Holstein-Friesian, 2,935 Jersey, and 3,609 crossbred Holstein-Friesian $\times$ Jersey cows, sampled an average of 3.42 times during the 2007-2008 season. Data were analyzed using univariate and bivariate repeatability animal models. Heritability of predicted FA concentration in milk fat ranged from 0.21 to 0.42 , indicating that genetic selection could be used to change the FA composition of milk. The de novo synthesized FA (C6:0, C8:0, C10:0, C12:0, and C14:0) showed strong positive genetic correlations with each other, ranging from 0.24 to 0.99 . Saturated FA were negatively correlated with unsaturated $(-0.93)$ and polyunsaturated $(-0.84)$ FA. The saturated FA were positively correlated with milk fat yield and fat percentage, whereas the unsaturated FA were negatively associated with fat yield and fat percentage. Our results indicate that bovine milk FA composition can be changed through genetic selection using MIR as a phenotypic proxy.

Key words: genetic correlations, infrared spectrometry, crossbreeding

Received November 27, 2019.

Accepted April 2, 2020.

*Corresponding author: N.Lopez-Villalobos@massey.ac.nz

\section{INTRODUCTION}

The breeding goal for New Zealand dairy cattle has been to increase net farm income per unit of feed, with little focus given to improving the composition of milk proteins and fatty acids (FA). Cow milk fat typically contains 70\% SFA, 25\% MUFA, and 5\% PUFA (Grummer, 1991). The FA composition of milk fat influences the technological properties of butter (MacGibbon and McLennan, 1987; MacGibbon and Taylor, 2006). Increasing the concentrations of $\mathrm{C} 18: 1$ and $\mathrm{C} 18: 2$ and reducing the concentrations of $\mathrm{C} 8: 0$ to $\mathrm{C} 14: 0 \mathrm{FA}$ improves the solid fat content at $10^{\circ} \mathrm{C}$ and, therefore, the spreadability of butter (MacGibbon and McLennan, 1987).

The concentration of FA in milk fat is affected by several factors (Hanuš et al., 2018), including diet (Palmquist et al., 1993; Dewhurst et al., 2006), stage of lactation and parity (Niero et al., 2016; Gottardo et al., 2017; Samková et al., 2018), and the natural genetic variation between cows (Soyeurt et al., 2006b; Stoop et al., 2008; Lehnert et al., 2015) and breeds (Auldist et al., 2004; Soyeurt et al., 2006b; Gottardo et al., 2017). Concentrations of individual FA are heritable (Arnould and Soyeurt, 2009; Krag et al., 2013; Bilal et al., 2014), indicating that there is sufficient genetic variation in FA content to implement a selection program to improve FA composition. However, the determination of individual concentrations of FA in individual cows through GC analyses is expensive and time consuming. Several studies (Soyeurt et al., 2006a; De Marchi et al., 2011; Lopez-Villalobos et al., 2014) have shown that it is possible to estimate FA concentrations by mid-infrared spectrometry. This technology is faster and cheaper than the reference chemical analysis. Using the predicted concentrations of individual FA by mid-infrared spectrometry, Soyeurt et al. (2006b, 2007) and Lopez-Villalobos et al. (2014) studied the genetic variation of $\mathrm{FA}$ and the differences across dairy breeds. 
Alteration of the fatty acid profile of cow milk can be desirable for 2 reasons (Hanuš et al., 2018): (1) from a human nutritional point of view, a lower proportion of SFA and a higher proportion of UFA, especially PUFA $\mathrm{n}-3$, is desirable; and (2) from a processability point of view, higher proportions of UFA are preferred (i.e., easier spreadability of butter is desirable for consumers). The relationship between the amount of SFA in the diet for humans and the incidence of cardiovascular and coronary heart diseases has been widely investigated over several decades. However, recent reviews still do not reach consensus as to risks to the consumer from saturated fat intake (Lopez-Huertas, 2010; Hanuš et al., 2018; German et al., 2019). There are also problems associated with having high UFA content in milk fat, including its lower stability, increased oxidation, and possible sensory changes.

The desired FA profile of cow milk is still unknown and, therefore, a directional change in the fatty acid profile is difficult. Gibson (1991) and Maijala (2000) concluded that it was difficult to define the desired direction of change in milk fat composition before 2000 . By 2009, Stoop (2009) reported that experts from the Netherlands suggested producing milk with lower fat percentage, lower proportions of $\mathrm{C} 14: 0$ and $\mathrm{C} 16: 0$, and higher proportions of UFA. At the present time (2020), the market for butter is forcing a reanalysis of these desired changes but based on updated knowledge on the effect of the FA profile on human health, milk fat processability into butter, cheese, and ice cream, shelf-life of dairy products, and flavors. If there were a market or processor drive for specific FA, this could be a method by which to alter the FA composition of milk and therefore the final product or product mix. Making desirable changes to the milk FA profile requires knowledge of the genetic and phenotypic correlations between FA to develop selection indices by which to select animals with the desired profile without affecting negatively production, reproduction, and survival traits. The objective of this study was to estimate genetic and phenotypic correlations for FA in pasture-fed New Zealand dairy cows.

\section{MATERIALS AND METHODS}

\section{Calibration Equations}

The method to develop the calibration equations to predict the most common FA was described by LopezVillalobos et al. (2014). A total of 848 milk samples were collected during the season 2003-2004 from 348 second-parity crossbred Holstein-Friesian $\times$ Jersey cows during peak, mid, and late lactation. These cows were part of a crossbreeding experiment designed to identify
QTL determining traits of economic importance in New Zealand dairy cattle (Spelman et al., 2001). Concentrations of FA in the 848 milk samples were determined by GC. The same milk samples were analyzed on a Foss MilkoScan FT6000 (Foss, Hillerød, Denmark) to provide the mid-infrared spectra. Wavenumbers related to water absorbance were removed from the spectra because these bands were found to have high noise levels (from 1,600 to 1,689 and from 3,048 to $3,666 \mathrm{~cm}^{-1}$ ).

A principal component analysis using SAS software (version 9.1; SAS Institute Inc., Cary, NC) was undertaken across all FA and whole spectra to calculate the Mahalanobis distance for each sample. A sample was considered an outlier when the value of the FA or spectrum differed from the mean of the population by 3 or more times the Mahalanobis distance. Using this threshold, 12 of the 848 samples were considered outliers and discarded.

The calibration equation for each FA was determined using partial least squares using SAS (version 9.1; SAS Institute Inc.). The optimum number of partial least squares (PLS) factors was determined by cross-validation from a maximum of 15 PLS factors allowed in the model. Fatty acid groups were defined by saturation (SFA and UFA) and by carbon chain length; shortchain (SCFA; 4 to 8 carbons), medium-chain (MCFA; 10 to 12 carbons), and long-chain (LCFA; 14 to 22 carbons). The coefficients of determination of crossvalidation $\left(\mathbf{R}_{\mathbf{C V}}^{2}\right)$ for the prediction equations were reported by Lopez-Villalobos et al. (2014). The $\mathrm{R}_{\mathrm{CV}}^{2}$ to predict C8:0, C10:0, C12:0, C18:1 cis-9, and for groups of FA C18:1, MCFA, LCFA, SFA, and UFA were $>0.8$, and those for C4:0, C6:0, C14:0, C16:0, and PUFA were $>0.70$. The $\mathrm{R}_{\mathrm{CV}}^{2}$ to predict $\mathrm{n}-3$ and $\mathrm{n}-6$ were lower $(0.44$ and 0.66 , respectively).

\section{Estimation of Breed Effects and Variance Components}

The calibration equations were used to predict the concentration of each FA in milk fat in 34,141 milk samples from 3,445 Holstein-Friesian, 2,935 Jersey, and 3,609 crossbred Holstein-Friesian $\times$ Jersey cows sampled, on average, 3.42 times during the 2007-2008 season. These milk samples were part of the herdtesting program used to determine concentrations of fat, protein, lactose, and SCC in a Foss MilkoScan FT6000 instrument (Foss). For statistical analysis, SCC was analyzed as SCS, calculated as $\log _{2}(\mathrm{SCC} / 1,000)$. The Fourier-transform infrared spectrum for each milk sample was provided by Livestock Improvement Corp. (Hamilton, New Zealand). The same statistical procedure applied to the calibration data set was followed in this data set. Wavenumbers related to water 
absorbance were removed and milk samples defined as outliers based on the Mahalanobis distance using principal components were discarded. No further edits were applied to the predicted values. The calibration data set (836 records) was merged with the prediction data set $(34,141$ records), and principal components analysis were performed on the spectra to evaluate variation in the spectra between the 2 data sets.

The cows were of different parities and distributed in 266 herds used for progeny testing of young bulls. The number of sires of the daughters providing records was 1,422. (Co)variance components to estimate heritability and repeatability for each predicted FA and genetic and phenotypic correlations among them were obtained using the statistical package ASReml version 3.0 (Gilmour et al., 2009) with univariate and bivariate repeatability animal models. In matrix notation, the bivariate model can be represented as follows:

$$
\left[\begin{array}{l}
\mathbf{y}_{1} \\
\mathbf{y}_{2}
\end{array}\right]=\left[\begin{array}{cc}
\mathbf{X}_{1} & \mathbf{0} \\
\mathbf{0} & \mathbf{X}_{2}
\end{array}\right]\left[\begin{array}{l}
\mathbf{b}_{1} \\
\mathbf{b}_{2}
\end{array}\right]+\left[\begin{array}{cc}
\mathbf{z}_{1} & \mathbf{0} \\
\mathbf{0} & \mathbf{Z}_{2}
\end{array}\right]\left[\begin{array}{l}
\mathbf{a}_{1} \\
\mathbf{a}_{2}
\end{array}\right]+\left[\begin{array}{cc}
\mathbf{W}_{1} & \mathbf{0} \\
\mathbf{0} & \mathbf{W}_{2}
\end{array}\right]\left[\begin{array}{l}
\mathbf{c}_{1} \\
\mathbf{c}_{2}
\end{array}\right]+\left[\begin{array}{l}
\mathbf{e}_{1} \\
\mathbf{e}_{2}
\end{array}\right],
$$

where $\mathbf{y}_{1}$ and $\mathbf{y}_{2}$ are the vectors of total lactation phenotypic measures for the 2 traits; $\mathbf{X}_{1}, \mathbf{X}_{2}, \mathbf{Z}_{1}, \mathbf{Z}_{2}, \mathbf{W}_{1}$, and $\mathbf{W}_{2}$ are design matrices relating the fixed, additive genetic, and cow permanent effects to the phenotypes, $\mathbf{b}_{1}$ and $\mathbf{b}_{2}$ are the vectors of fixed effects of parity number (1 to 10), herd-test-day, month of calving, the proportion of Jersey (proportion of Holstein-Friesian was not included in the model to avoid linear dependencies and was used as a base for comparison), heterosis Holstein-Friesian $\times$ Jersey for cows with records, $\mathbf{a}_{1}$ and $\mathbf{a}_{2}$ are the vectors of random effects of animal for each trait, $\mathbf{c}_{1}$ and $\mathbf{c}_{2}$ are the vectors of random effects of cow permanent environment for each trait, and $\mathbf{e}_{1}$ and $\mathbf{e}_{2}$ are vectors of residual errors. The distributional properties of the model with $E$ and Var indicating the expectation and variance were as follows:

$$
E\left[\begin{array}{l}
\mathbf{y}_{1} \\
\mathbf{y}_{2}
\end{array}\right]=\left[\begin{array}{cc}
\mathbf{X}_{1} & \mathbf{0} \\
\mathbf{0} & \mathbf{X}_{2}
\end{array}\right]\left[\begin{array}{l}
\mathbf{b}_{1} \\
\mathbf{b}_{2}
\end{array}\right]
$$

and

$$
\operatorname{Var}\left[\begin{array}{c}
\mathbf{a}_{1} \\
\mathbf{a}_{2} \\
\mathbf{c}_{1} \\
\mathbf{c}_{2} \\
\mathbf{e}_{1} \\
\mathbf{e}_{2}
\end{array}\right]=\left[\begin{array}{cccccc}
\mathbf{A} \sigma_{a 1}^{2} & \mathbf{A} \sigma_{a 1 a 2} & \mathbf{0} & \mathbf{0} & \mathbf{0} & \mathbf{0} \\
\mathbf{A} \sigma_{a 1 a 2} & \mathbf{A} \sigma_{a 2}^{2} & \mathbf{0} & \mathbf{0} & \mathbf{0} & \mathbf{0} \\
\mathbf{0} & \mathbf{0} & \mathbf{I}_{1} \sigma_{c 1}^{2} & \mathbf{I}_{1} \sigma_{c 1 c 2} & \mathbf{0} & \mathbf{0} \\
\mathbf{0} & \mathbf{0} & \mathbf{I}_{1} \sigma_{c 1 c 2} & \mathbf{I}_{1} \sigma_{c 2}^{2} & \mathbf{0} & \mathbf{0} \\
\mathbf{0} & \mathbf{0} & \mathbf{0} & \mathbf{0} & \mathbf{I}_{2} \sigma_{e 1}^{2} & \mathbf{I}_{2} \sigma_{e 1 e 2} \\
\mathbf{0} & \mathbf{0} & \mathbf{0} & \mathbf{0} & \mathbf{I}_{2} \sigma_{e 1 e 2} & \mathbf{I}_{2} \sigma_{e 2}^{2}
\end{array}\right],
$$

where $\mathbf{A}$ is the numerator relationship matrix of order equal to the total number of animals in the pedigree file; $\sigma_{a 1}^{2}, \quad \sigma_{a 2}^{2}$, and $\sigma_{a 1 a 2}$ are the animal (co)variance components for the 2 traits; $\mathbf{I}_{1}$ is an identity matrix of order equal to the number of animals with lactation records; $\sigma_{c 1}^{2}, \sigma_{c 2}^{2}$, and $\sigma_{c 1 c 2}$ are the cow permanent (co) variance components for the traits; $\mathbf{I}_{2}$ is an identity matrix of order equal to the number of records; and $\sigma_{e 1}^{2}, \quad \sigma_{e 2}^{2}$, and $\sigma_{e 1 e 2}$ are the residual (co)variance components for the traits. Heritability $\left(h^{2}\right)$ and repeatability $(t)$ of a trait were calculated as

$$
\begin{gathered}
h^{2}=\frac{\sigma_{a}^{2}}{\sigma_{p}^{2}} \text { and } \\
t=\frac{\sigma_{a}^{2}+\sigma_{c}^{2}}{\sigma_{p}^{2}},
\end{gathered}
$$

and genetic $\left(r_{G}\right)$ and phenotypic $\left(r_{P}\right)$ correlations were calculated as

$$
\begin{gathered}
r_{G}=\frac{\sigma_{a 1 a 2}}{\sigma_{a 1} \times \sigma_{a 2}} \text { and } \\
r_{P}=\frac{\sigma_{p 1 p 2}}{\sigma_{p 1} \times \sigma_{p 2}},
\end{gathered}
$$

where $\sigma_{P}^{2}$ is the phenotypic variance for any trait calculated as $\sigma_{P}^{2}=\sigma_{a}^{2}+\sigma_{c}^{2}+\sigma_{e}^{2}$.

\section{RESULTS}

\section{Mean and Coefficient of Variation}

Descriptive statistics of daily milk production levels and concentrations of the main FA are presented in Table 1 . Mean daily milk yield was $17.07 \mathrm{~L} / \mathrm{d}$ and contents of fat, protein and lactose were 4.93, 3.79, and $4.87 \%$, respectively. Milk yield traits had higher coefficients of variation $(\mathbf{C V})$ than contents of milk components and FA. A low CV (4\%) was found for SCFA (C4:0 to C8:0) and higher CV (13\%) was found for MCFA. The highest CV were found for n-6 (23\%), C18:2 cis-9,trans-11 (26\%), and C20:0 (33\%). The CV for the entire SFA and UFA were low, 4 and 9\%, respectively, and PUFA had a higher CV (11\%).

Saturated FA averaged $71.09 \%$, UFA averaged $28.95 \%$, and PUFA averaged $4.10 \%$ of the total FA. 
The most abundant SFA were C14:0, C16:0. and C18:0, averaging $10.53,23.92$, and $12.20 \%$ of the total FA, respectively. The FA C18:1 cis-9, the most prominent among the UFA, averaged $16.95 \%$ of the total FA. The mean of LCFA was $78.75 \%$, with a large range from 66.93 to 100.29\%. Supplemental Figure S1 (https:// doi.org/10.3168/jds.2019-17971) shows the distribution of milk samples from the 2 data sets (calibration and prediction) along the 2 principal components. It can be observed that the calibration data set is fully represented in the prediction data set.

\section{Heritabilities and Repeatabilities}

Estimates of variance components, heritabilities, and repeatabilities of daily milk yields and concentration of the main FA are presented in Table 2. These estimates were obtained using the univariate repeatability animal model. Estimates of heritability and repeatability for percentages of fat, protein, and lactose were higher than the respective estimates for yields of fat, protein, and lactose. Estimates of $h^{2}$ for SFA were higher than estimates of $h^{2}$ for UFA and PUFA. The standard errors of

Table 1. Descriptive statistics of daily yields of milk, fat, protein and lactose, and concentrations of fat, protein, lactose, and fatty acids (FA) in New Zealand cows sampled in $2007(\mathrm{n}=34,140)$

\begin{tabular}{|c|c|c|c|c|c|}
\hline Trait & Mean & $\mathrm{SD}$ & $\mathrm{CV}$ & Minimum & Maximum \\
\hline Milk yield, kg/d & 17.07 & 6.45 & 38 & 0.60 & 50.20 \\
\hline Fat yield, $\mathrm{kg} / \mathrm{d}$ & 0.81 & 0.27 & 33 & 0.02 & 2.34 \\
\hline Protein yield, kg/d & 0.63 & 0.22 & 35 & 0.02 & 1.97 \\
\hline Lactose yield, $\mathrm{kg} / \mathrm{d}$ & 0.83 & 0.32 & 39 & 0.03 & 2.51 \\
\hline Fat, $\%$ & 4.93 & 0.92 & 19 & 2.22 & 8.11 \\
\hline Protein, \% & 3.79 & 0.42 & 11 & 2.55 & 5.73 \\
\hline Lactose, \% & 4.87 & 0.19 & 4 & 4.23 & 5.40 \\
\hline $\mathrm{SCS}^{1}$ & 6.33 & 1.65 & 26 & 2.32 & 14.27 \\
\hline \multicolumn{6}{|c|}{ Fatty acid, $\%$ of total FA } \\
\hline $\mathrm{C} 4: 0$ & 4.14 & 0.23 & 6 & 2.95 & 4.89 \\
\hline $\mathrm{C} 6: 0$ & 2.62 & 0.12 & 5 & 2.10 & 3.24 \\
\hline $\mathrm{C} 8: 0$ & 1.64 & 0.11 & 7 & 1.14 & 2.19 \\
\hline C10:0 & 3.63 & 0.40 & 11 & 1.91 & 5.49 \\
\hline C10:1 & 0.26 & 0.04 & 15 & 0.14 & 0.44 \\
\hline C12:0 & 3.79 & 0.54 & 14 & 1.81 & 6.19 \\
\hline C12:1 & 0.13 & 0.02 & 15 & 0.08 & 0.21 \\
\hline C14:0 & 10.53 & 1.03 & 10 & 7.15 & 14.98 \\
\hline C16:0 & 23.92 & 2.39 & 10 & 16.71 & 32.97 \\
\hline C18:0 & 12.20 & 2.77 & 23 & 1.44 & 25.45 \\
\hline C18:1 cis-9 & 16.95 & 2.37 & 14 & 8.39 & 24.76 \\
\hline C18:1 cis -7 & 4.64 & 0.96 & 21 & 1.44 & 8.04 \\
\hline $\mathrm{C} 18: 2$ cis-9, cis-12 & 1.21 & 0.21 & 17 & 0.52 & 2.13 \\
\hline C18:2 cis-9,trans-11 & 0.84 & 0.22 & 26 & 0.01 & 1.77 \\
\hline C20:0 & 0.12 & 0.04 & 33 & 0.01 & 0.22 \\
\hline$n-3^{2}$ & 1.12 & 0.18 & 16 & 0.50 & 1.84 \\
\hline$n-6^{3}$ & 1.28 & 0.29 & 23 & 0.23 & 2.36 \\
\hline $\mathrm{SCFA}^{4}$ & 8.40 & 0.37 & 4 & 6.45 & 10.13 \\
\hline $\mathrm{MCFA}^{5}$ & 7.81 & 0.97 & 13 & 4.06 & 12.17 \\
\hline $\mathrm{LCFA}^{6}$ & 78.75 & 4.51 & 6 & 66.93 & 100.29 \\
\hline $\mathrm{SFA}^{7}$ & 71.09 & 3.01 & 4 & 59.73 & 81.97 \\
\hline $\mathrm{UFA}^{8}$ & 28.95 & 2.75 & 9 & 18.44 & 37.81 \\
\hline $\mathrm{PUFA}^{9}$ & 4.10 & 0.47 & 11 & 2.42 & 5.86 \\
\hline
\end{tabular}

${ }^{1}$ Calculated as $\log _{2}(\mathrm{SCC} / 1,000)$.

${ }^{2} \mathrm{n}-3=$ sum of all $\mathrm{n}-3$ fatty acids.

${ }^{3} \mathrm{n}-6=$ sum of all $\mathrm{n}-6$ fatty acids.

${ }^{4} \mathrm{SCFA}=$ short-chain fatty acids; sum of C4:0, C6:0, and C8:0.

${ }^{5} \mathrm{MCFA}=$ medium-chain fatty acids; sum of C10:0, C10:1, C12:0, and C12:1.

${ }^{6} \mathrm{LCFA}=$ long-chain fatty acids; sum from C14:0 to C22:0.

${ }^{7} \mathrm{SFA}=$ sum of C4:0, C6:0, C8:0, C10:0, C12:0, C13:0, C14:0, C15:0, C16:0, C17:0, C18:0, C20:0, and C22:0.

${ }^{8} \mathrm{UFA}=$ sum of PUFA and C10:1, C12:1, C14:1, C16:1, C17:1, C18:1 cis-9, C18:1 trans-11, C20:1 cis-11, and C24:1.

${ }^{9} \mathrm{PUFA}=$ sum of C18:2 cis-9,trans-11, C18:3n-3 cis-9, cis-12,cis-15, C20:2n-6 cis-11,cis-14, C20:3n-6 cis-8, cis11,cis-14, C20:4n-6 cis-5,cis-8,cis-11,cis-14, C20:3n-3 cis-11,cis-14,cis-17, C20:4n-3 cis-8,cis-11,cis-14,cis-17, C20:5n-3 cis-5,cis-8,cis-11,cis-14,cis-17, C22:4n-6 cis-7,cis-10,cis-13,cis-16, C22:5n-6 cis-4,cis-7,cis-10,cis13,cis-16, C22:5n-3 cis-7, cis-10,cis-13,cis-16,cis-19, and C22:6n-3 cis-4,cis-7,cis-10,cis-13,cis-16,cis-19. 
$h^{2}$ estimates were $\leq 0.03$. The highest $h^{2}$ estimates were for C16:0 and C20:0 (0.42), and the lowest $h^{2}$ estimates were for C18:1 cis-7 (0.21) and C18:2 cis-9,trans-11 $(0.21)$.

\section{Correlations Among Production Traits}

The genetic and phenotypic correlations among all traits considered in this study are presented in Table 3 . The standard errors of these estimates were $\leq 0.06$. The correlations between yields traits were high and positive. The genetic correlations of milk yield with fat percentage and protein percentage were moderate and negative $(-0.52$ and -0.53 , respectively) and the corresponding phenotypic correlations were also negative but weaker $(-0.26$ and -0.36$)$.

Milk and protein yields had positive genetic correlations with SCFA and negative correlations with MCFA and LCFA. Milk and protein yields had a negative genetic correlation with SFA and positive correlations with UFA and PUFA. Fat yield had the opposite trend, being negatively correlated with SCFA, UFA, and

Table 2. Estimates of variances, heritability, and repeatability for production traits and concentrations of fatty acids (FA) in New Zealand dairy cattle

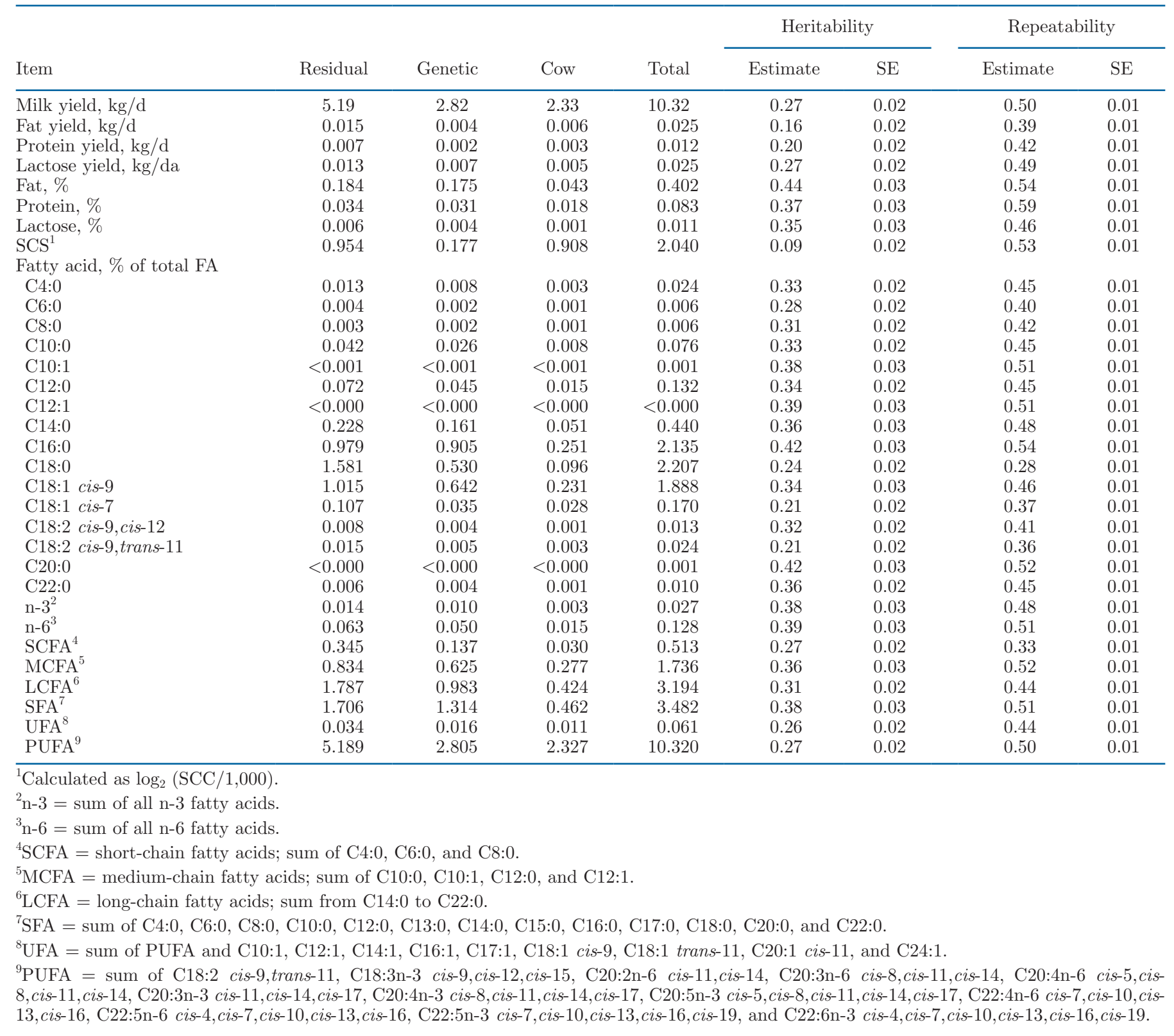


Table 3. Phenotypic (above the diagonal) and genetic (below the diagonal) correlations between fatty acids (FA) in New Zealand dairy cattle

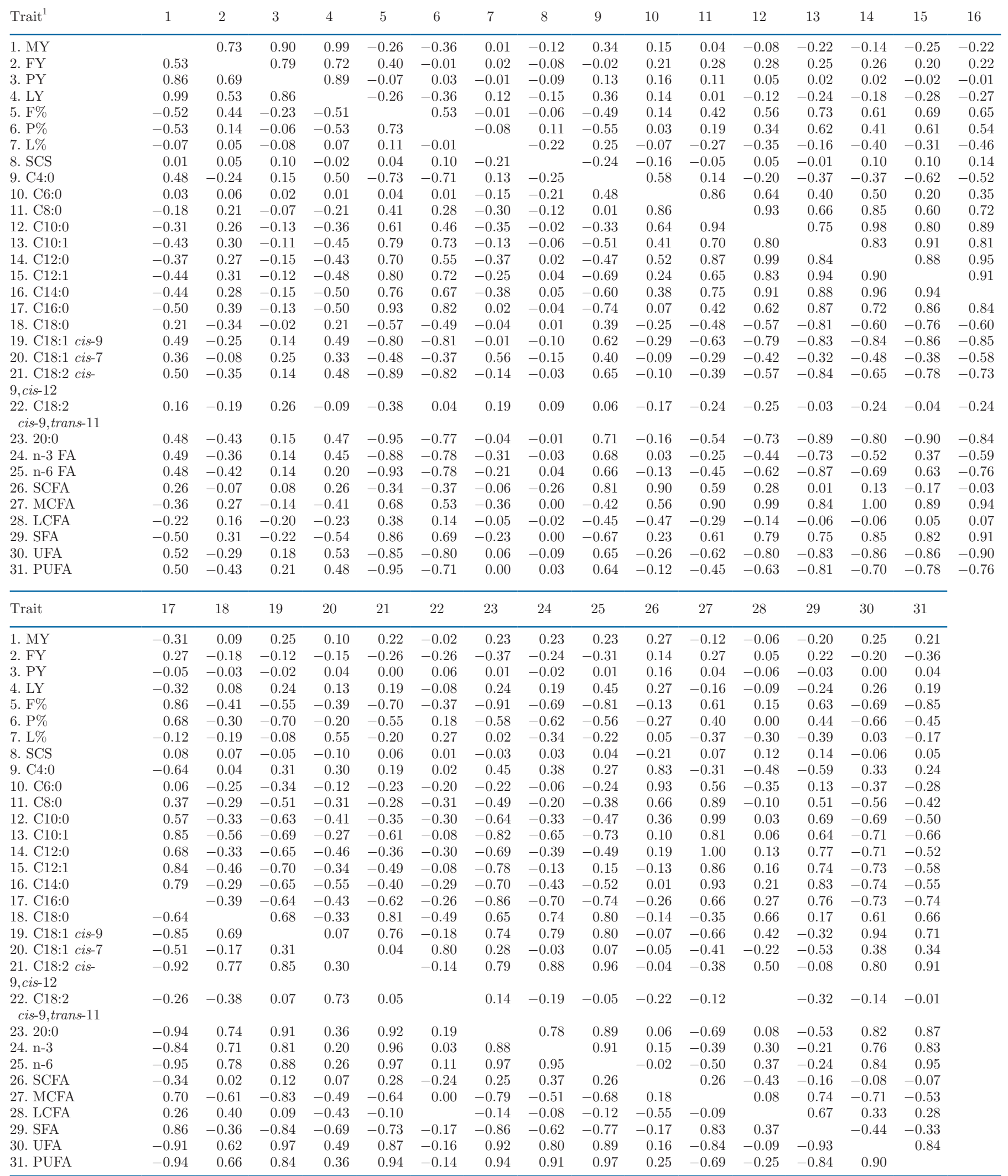

${ }^{1} \mathrm{MY}=$ milk yield, $\mathrm{FY}=$ fat yield, $\mathrm{PY}=$ protein yield, $\mathrm{LY}=$ lactose yield, $\mathrm{F} \%=$ fat percentage, $\mathrm{P} \%=$ protein percentage, $\mathrm{L} \%=$ lactose percentage; $\mathrm{SCFA}$ $=$ short-chain fatty acids; MCFA = medium-chain fatty acids; LCFA = long-chain fatty acids. All groups are as defined in Table 1 . 
PUFA and positively correlated with SFA. The phenotypic and genetic correlations of SCS with the different FA were low, except for a moderate negative correlation with $\mathrm{C} 4: 0$ and $\mathrm{C} 6: 0$. The genetic and phenotypic correlations of milk yield with n-3 and n- 6 FA were moderately positive.

Fat and protein percentage had positive genetic correlations with SFA and negative correlations with UFA and PUFA. Among individual FA, fat percentage had a strong positive (0.93) genetic correlation with C16:0 and a strong negative $(-0.80)$ correlation with C18:1 cis-9. The genetic correlation between $\mathrm{C} 18: 0$ and fat percentage was moderately negative $(-0.57)$ and that between $\mathrm{C} 12: 0$ and fat percentage was positive (0.70).

\section{Genetic Correlations Among De Novo Fatty Acids}

Strong positive genetic and phenotypic correlations among C6:0 to C16:0 were found in this study (Table 3). However, the correlations of C4:0 with other FA did not follow the same trend. The $\mathrm{C} 4: 0$ had a moderate positive genetic correlation with $\mathrm{C} 6: 0$, zero with $\mathrm{C} 8: 0$, negative with C10:0, C10:1, C12:0, C14:0 and C16:0, and positive with FA C18:0 or greater.

The genetic correlations of C16:0 with C4:0, C18:0, and $\mathrm{C} 20: 0$ and all of the FA of the C18:1 and C18:2 groups were moderately to strongly negative, but genetic correlations of C16:0 with C8:0, C10:0, C10:1, C12:0, $\mathrm{C} 12: 1$, and C14:0 were strongly positive (from 0.42 to 0.87). The phenotypic correlations of $\mathrm{C} 18: 0$ and $\mathrm{C} 18: 1$ cis-9 with saturated short to medium-chain FA (C6:0, C8:0, C10:0, C12:0, C14:0, and C16:0) were negative. The SFA had negative correlations with UFA $(-0.93)$ and PUFA ( -0.84$)$ and the genetic correlation between UFA and PUFA was strong and positive (0.90).

The genetic and phenotypic correlations between n-3 and $n-6$ were strong and positive. The phenotypic and genetic correlations of $\mathrm{n}-3$ and n-6 with C4:0, C18:0, and C18:1 cis-9 were strongly positive, whereas correlations with $\mathrm{C} 10: 0, \mathrm{C} 01: 1, \mathrm{C} 12: 0, \mathrm{C} 14: 0$, and $\mathrm{C} 16: 0$ were strong and negative.

\section{DISCUSSION}

\section{Mean and Coefficient of Variation}

The levels of milk production found in this study were similar to other values reported in New Zealand (Auldist et al., 2004) in cows under grazing conditions. However, the cows in this study produced less milk with higher concentrations of fat and protein compared with Canadian Holstein cows fed TMR (Fleming et al., 2018) or Italian Brown Swiss, Holstein-Friesian, Jersey,
Simmental, and Alpine Grey cows fed forage or hay and concentrate (Manuelian et al., 2019). The mean values of the FA found in this study were typical of New Zealand dairy cattle (MacGibbon, 1996; Auldist et al., 2004). Of the total FA, $71.09 \%$ were SFA and $28.95 \%$ were UFA, which were similar to other reported populations (Grummer, 1991). The concentration of PUFA was $4.10 \%$, which agrees well with the value reported by Grummer (1991). MacGibbon and Taylor (2006) reported C16 and C18:1 as the major FA in milk in New Zealand. The mean reported values were 27.9 and $17.2 \%$, respectively, with ranges of 23.6 to $31.4 \%$ and 14.9 to $22 \%$ respectively. These values agree with the values estimated in this study. The ratio of $n-6$ to n-3 estimated in this study was 1.14, which is similar to that for US organic milk and desirable for human health (Benbrook et al., 2013). The optimal ratio of n-6 to n-3 FA is estimated to be close to 2.0. An excess of n-6 FA can interfere with the utilization of n-3 FA and thereby limit their numerous health benefits, such as reducing the risk of cardiovascular disease, diabetes, and obesity (Benbrook et al., 2013). Some predicted values of LCFA were $100 \%$, which indicates some level of overprediction by the calibration equation using midinfrared spectra.

\section{Heritabilities and Repeatabilities}

Heritabilities and repeatabilities for yields of milk, fat, and protein and for concentrations of fat, protein, and lactose found in this study agree well with other estimates in New Zealand dairy cattle (Sneddon et al., 2015). The estimates of heritabilities for FA in this study were generally higher than those reported by Bobe et al. (2008) in American Holstein cows, by Mele et al. (2009) in Italian Holstein cows, by Soyeurt et al. (2007) in mixed-breed population of the Walloon region of Belgium, and by Krag et al. (2013) in Danish Holstein cows, but agree well with the estimates reported by Stoop (2009) in Dutch Holstein cows. The estimates of heritabilities for FA reported by Pegolo et al. (2016) in Italian Brown Swiss cows were obtained from a well-designed experiment and FA were determined using GC, with variance components estimated using Bayesian animal models. Their estimates were, in general, lower than ours, and those authors argued that comparisons of heritability estimates among the various studies are difficult because of differences in the analytical methods (GC or spectroscopy), the method of expressing FA contents (g/100 g of milk, g of FA/100 $\mathrm{g}$ of fat, or $\mathrm{g}$ of FA/100 $\mathrm{g}$ of total FA), sample size, breed, parity number, stage of lactation, and the statistical methods (e.g., sire, animal model and random 
regression). However, the heritability estimates for FA indicate that differential selection could be used to change the FA composition of milk through genetics.

The estimates of repeatabilities for FA found in this study were, in general, higher than those reported by Bobe et al. (2008) in American Holstein cows and by Soyeurt et al. (2007) in dairy cattle from different breeds in the Walloon region of Belgium. Our estimates of repeatabilities for FA indicate that cows with a high proportion of a particular FA maintained that consistently high level throughout the lactation.

\section{Correlations Among Production Traits}

The estimates of phenotypic and genetic correlations between yield traits were similar to the values reported in other studies, including lactose (Sneddon et al., 2015; Costa et al., 2019).

Somatic cell score and lactation yields of milk, fat, and protein are traits included in the breeding objective of New Zealand dairy cattle. The economic values of these traits used in the genetic evaluation of February 2019 were $-\$ 37.3 /$ unit of SCS, $-\$ 0.092 / \mathrm{L}$ of milk, $\$ 3.49 / \mathrm{kg}$ of fat, and $\$ 4.38 / \mathrm{kg}$ of protein.

The current study estimated phenotypic and genetic correlations of milk production traits and SCS with FA to be used for later studies and predicted correlated responses under different selection scenarios to modify the fatty acid profile of the New Zealand milk. In the Netherlands, Stoop (2009) used selection index theory to illustrate that selection for protein yield could produce positive correlated responses in the proportions of C14:0 and UFA and negative correlated responses in the proportions of C16:0 in milk fat of Dutch Holstein cattle.

The phenotypic and genetic correlations of SCS with the different FA were generally low, except for a moderate negative correlation with $\mathrm{C} 4: 0$ and $\mathrm{C} 6: 0$. Soyeurt et al. (2007) and Bilal et al. (2014) reported that SFA (C12:0, C14:0, C16:0, and C18:0) tended to be negatively correlated with milk yield, but UFA (C18:1 and C18:2) had weak positive correlations with milk yield. The results from this study confirm the strong negative association of milk yield with C12:0 and C14:0, but the genetic correlations of milk yield with unsaturated C18:1 and C18:2 were moderately positive in the present study. Interestingly, the genetic and phenotypic correlations of milk yield with n-3 and n- 6 FA were moderately positive. These correlation estimates suggest that positive correlated responses would be expected when milk yield is increased. However, in the construction of selection indices to modify the concentrations of n-3 and $\mathrm{n}-6$ in milk fat, the strong and negative correlations (from -0.78 to -0.93 ) of these FA with fat and protein percentages need to be considered (Table 3).

Several studies (Soyeurt et al., 2007; Stoop et al., 2008; Bilal et al., 2014) have reported that fat and protein percentages have positive genetic correlations with SFA and negative correlations with UFA and PUFA, indicating that genetic gains in the concentrations of fat and protein in milk may result in fat with higher content of SFA but lower contents of UFA and PUFA.

The strong positive genetic correlation between fat percentage and C16:0 and the strong negative genetic correlation between fat percentage and C18:1 cis-9 found in this study were also reported by Schennink et al. (2007) and Stoop et al. (2008) in Dutch Holsteins and by Bilal et al. (2014) in Canadian Holsteins. This suggests that selection against high palmitic acid (C16:0) concentration in milk fat will lead to low milk fat percentage, which might be undesirable for the dairy industry from an economic perspective (Nafikov et al., 2015). However, Soyeurt et al. (2007), in a study with multiple breeds, noted that not all SFA were negatively correlated with fat percentage. They reported that the genetic correlation between $\mathrm{C} 18: 0$ and fat percentage was high (0.84). Bilal et al. (2014) reported in Canadian Holsteins a negative correlation $(-0.10)$. In our study, the corresponding genetic correlation was moderate and negative $(-0.57)$. This apparent contradiction may be due to the underlying genetics of the crossbred cows used in our study.

In agreement with other studies (Soyeurt et al., 2007; Bilal et al., 2014), the genetic correlation between C18:1 and fat percentage was strong and negative $(-0.80)$. MacGibbon (1996) illustrated that concentration of C18:1 was negatively correlated with the hardness of the milk fat.

\section{Genetic Correlations Among De Novo Synthesized Fatty Acids}

Even-chain saturated $\mathrm{C} 6: 0-\mathrm{C} 14: 0$ and a fraction of C16:0 are synthesized de novo in the mammary gland from SCFA formed by microbial digestion of carbohydrates in the rumen (Palmquist et al., 1993); therefore, strong positive genetic and phenotypic correlations among these FA were estimated in this study. Similar results were reported by Karijord et al. (1982) in Norway, Krag et al. (2013) and Buitenhuis et al. (2014) in Denmark, Bilal et al. (2014) in Canada, and Pegolo et al. (2016) in Italy. The phenotypic and genetic correlations of C4:0 with other de novo synthesized FA in the mammary gland were zero or negative. This 
trend was similar to the trend reported by Stoop et al. (2008) in Dutch Holstein cows and by Bilal et al. (2014) in Canadian Holstein cows. The genetic correlations of C16:0 with C8:0, C10:0, C10:1, C12:0, C12:1, and $\mathrm{C} 14: 0$ were strong and positive (from 0.42 to 0.87 ); C18:0 showed the opposite correlations to C16:0. This difference for C18:0 is likely because C18:0 is part of a group of FA absorbed from blood, whereas a fraction of the $\mathrm{C} 16: 0$ is synthesized de novo in the mammary gland. The C18:0 in the blood is a consequence of the extent of biohydrogenation in the rumen of C18 UFA from the feed. Thus, the concentrations of C16:0 and C18:0 in milk fat are influenced by different factors (Palmquist et al., 1993). Oleic acid (C18:1 cis-9) can be produced from stearic acid (C18:0) under the action of $\Delta^{9}$-desaturase enzyme activity. The genetic and phenotypic correlations between C18:0 and C18:1 cis-9 were strong and positive (0.69 and 0.68). Pegolo et al. (2016) also reported a positive genetic correlation (0.60) between these $2 \mathrm{FA}$. The negative genetic correlations of C18:1 with saturated short- to medium-chain FA (C6:0, C8:0, C10:0, C12:0, C14:0, and C16:0) could be due to the known effect of C18:1 as the main compensation for changes in SCFA (Palmquist et al., 1993). The mid to strong (negative) phenotypic correlations of C18:0 and C18:1 cis-9 with saturated short- to medium-chain FA (C6:0, C8:0, C10:0, C12:0, C14:0, and C16:0) may be also explained because these cows were grazing pasture with high amounts of $\mathrm{C} 18: 0$ and C18:1 decreasing the de novo fat synthesis of saturated short- to mediumchain FA (C6:0, C8:0, C10:0, C12:0, C14:0; Grummer, 1991; Hurtaud et al., 2010). The genetic correlation between SCFA and LCFA in our study was -0.55 , which is opposite to the reported value of 0.70 reported by Narayana et al. (2017). This apparent contradiction may be explained by the differences in the definitions of the length of the carbon chain, and the expression of concentration of FA; in our study, FA were expressed as grams per $100 \mathrm{~g}$ of total FA, whereas the Narayana et al. (2017) expressed concentration as grams per 100 $\mathrm{g}$ of milk.

The strong negative genetic correlation between SFA and UFA found in this study has also been reported in most studies (Krag et al., 2013; Buitenhuis et al., 2014; Pegolo et al., 2016; Hein et al., 2018), although other studies (Soyeurt et al., 2007; Narayana et al., 2017) have reported strong $(>0.6)$ positive genetic correlations over the lactation. This apparent contradiction is due to the expression of concentration of FA; Soyeurt et al. (2007) and Narayana et al. (2017) expressed concentration as grams per $100 \mathrm{~g}$ of milk, whereas the other studies expressed concentration as grams per $100 \mathrm{~g}$ of total FA.

\section{CONCLUSIONS}

The current study provided estimates of genetic and phenotypic correlations between milk production traits and content of FA in New Zealand dairy cattle. These estimates suggest that the FA profile must have been changed as a result of current selection indices and breeding objectives of the dairy industry. The estimates of genetic parameters reported in this study are useful data for the definition of feeding or breeding strategies aimed at improving milk with better characteristics for human health and improved processing ability of highfat dairy products.

\section{ACKNOWLEDGMENTS}

This research was funded by Vialactia Biosciences (NZ) Ltd., a subsidiary of Fonterra, and a New Zealand Government FRST grant Super cows: superfoods! RGS, KL, and SDB are former employees of ViaLactia Biosciences (NZ) Ltd. The authors acknowledge the assistance of farm and technical staff in collecting milk samples. The authors have not stated any conflicts of interest.

\section{REFERENCES}

Arnould, V. M.-R., and H. Soyeurt. 2009. Genetic variability of milk fatty acids. J. Appl. Genet. 50:29-39. https://doi.org/10.1007/ BF03195649.

Auldist, M. J., K. A. Johnston, N. J. White, W. P. Fitzsimons, and M. J. Boland. 2004. A comparison of the composition, coagulation characteristics and cheesemaking capacity of milk from Friesian and Jersey dairy cows. J. Dairy Res. 71:51-57. https://doi.org/10 $.1017 /$ S0022029903006575.

Benbrook, C. M., G. Butler, M. A. Latif, C. Leifert, and D. R. Davis. 2013. Organic production enhances milk nutritional quality by shifting fatty acid composition: A United States-wide, 18-month study. PLoS One 8:e82429. https://doi.org/10.1371/journal.pone .0082429 .

Bilal, G., R. I. Cue, A. F. Mustafa, and J. F. Hayes. 2014. Short communication: Genetic parameters of individual fatty acids in milk of Canadian Holsteins. J. Dairy Sci. 97:1150-1156. https://doi.org/ 10.3168/jds.2012-6508.

Bobe, G., J. A. Minick Bormann, G. L. Lindberg, A. E. Freeman, and D. C. Beitz. 2008. Short Communication: Estimates of genetic variation of milk fatty acids in US Holstein cows. J. Dairy Sci. 91:1209-1213. https://doi.org/10.3168/jds.2007-0252.

Buitenhuis, B., L. L. Janss, N. A. Poulsen, L. B. Larsen, M. K. Larsen, and P. Sørensen. 2014. Genome-wide association and biological pathway analysis for milk-fat composition in Danish Holstein and Danish Jersey cattle. BMC Genomics 15:1112. https://doi.org/10 .1186/1471-2164-15-1112.

Costa, A., N. Lopez-Villalobos, G. Visentin, M. De Marchi, M. Cassandro, and M. Penasa. 2019. Heritability and repeatability of milk lactose and its relationships with traditional milk traits, somatic cell score and freezing point in Holstein cows. Animal 13:909-916. https://doi.org/10.1017/S1751731118002094.

De Marchi, M., M. Penasa, A. Cecchinato, M. Mele, P. Secchiari, and G. Bittante. 2011. Effectiveness of mid-infrared spectroscopy to predict fatty acid composition of Brown Swiss bovine milk. Animal 5:1653-1658. https://doi.org/10.1017/S1751731111000747. 
Dewhurst, R. J., K. J. Shingfield, M. R. F. Lee, and N. D. Scollan. 2006. Increasing the concentrations of beneficial polyunsaturated fatty acids in milk produced by dairy cows in high-forage systems. Anim. Feed Sci. Technol. 131:168-206. https://doi.org/10.1016/j .anifeedsci.2006.04.016.

Fleming, A., F. S. Schenkel, F. Malchiodi, R. A. Ali, B. Mallard, M. Sargolzaei, J. Jamrozik, J. Johnston, and F. Miglior. 2018. Genetic correlations of mid-infrared-predicted milk fatty acid groups with milk production traits. J. Dairy Sci. 101:4295-4306. https://doi .org/10.3168/jds.2017-14089.

German, J. B., N. Argov-Argaman, and B. J. Boyd. 2019. Milk lipids: A complex nutrient delivery system. Nestle Nutr. Inst. Workshop Ser. 90:217-225. https://doi.org/10.1159/000490320.

Gibson, J. P. 1991. The potential for genetic change in milk fat composition. J. Dairy Sci. 74:3258-3266. https://doi.org/10.3168/jds .S0022-0302(91)78511-1.

Gilmour, A. R., B. J. Gogel, B. R. Cullis, and R. Thompson. 2009 ASReml User Guide Release 3.0. VSN International Ltd., Hemel Hempstead, UK.

Gottardo, P., M. Penasa, F. Righi, N. Lopez-Villalobos, M. Cassandro, and M. De Marchi. 2017. Fatty acid composition of milk from Holstein-Friesian, Brown Swiss, Simmental and Alpine Grey cows predicted by mid-infrared spectroscopy. Ital. J. Anim. Sci. 16:380389. https://doi.org/10.1080/1828051X.2017.1298411.

Grummer, R. R. 1991. Effect of feed on the composition of milk fat. J. Dairy Sci. 74:3244-3257. https://doi.org/10.3168/jds.S0022 $-0302(91) 78510-\mathrm{X}$

Hanuš, O., E. Samková, L. Kř́žová, L. Hasoňová, and R. Kala. 2018. Role of fatty acids in milk fat and the influence of selected factors on their variability-A review. Molecules 23:1636. https://doi.org/ 10.3390/molecules23071636.

Hein, L., L. P. Sørensen, M. Kargo, and A. J. Buitenhuis. 2018. Genetic analysis of predicted fatty acid profiles of milk from Danish Holstein and Danish Jersey cattle populations. J. Dairy Sci. 101:2148-2157. https://doi.org/10.3168/jds.2017-13225.

Hurtaud, C., F. Faucon, S. Couvreur, and J. L. Peyraud. 2010. Linear relationship between increasing amounts of extruded linseed in dairy cow diet and milk fatty acid composition and butter properties. J. Dairy Sci. 93:1429-1443. https://doi.org/10.3168/jds.2009 -2839 .

Karijord, Ø., N. Standal, and O. Syrstad. 1982. Sources of variation in composition of milk fat. Z. Tierzuecht. Zuechtungsbiol. 99:81-93. https://doi.org/10.1111/j.1439-0388.1982.tb00367.x.

Krag, K., N. A. Poulsen, M. K. Larsen, L. B. Larsen, L. L. Janss, and B. Buitenhuis. 2013. Genetic parameters for milk fatty acids in Danish Holstein cattle based on SNP markers using a Bayesian approach. BMC Genet. 14:79. https://doi.org/10.1186/1471-2156 $-14-79$.

Lehnert, K., H. Ward, S. D. Berry, A. Ankersmit-Udy, A. Burrett, E. M. Beattie, N. L. Thomas, B. Harris, C. A. Ford, S. R. Browning, P. Rawson, G. A. Verkerk, Y. van der Does, L. F. Adams, S. R. Davis, T. W. Jordan, A. K. H. MacGibbon, R. J. Spelman, and R. G. Snell. 2015. Phenotypic population screen identifies a new mutation in bovine DGAT1 responsible for unsaturated milk fat. Sci. Rep. 5:8484. https://doi.org/10.1038/srep08484.

Lopez-Huertas, E. 2010. Health effects of oleic acid and long chain omega-3 fatty acids (EPA and DHA) enriched milks. A review of intervention studies. Pharmacol. Res. 61:200-207. https://doi.org/ 10.1016/j.phrs.2009.10.007.

Lopez-Villalobos, N., R. J. Spelman, J. Melis, S. R. Davis, S. D. Berry, K. Lehnert, S. E. Holroyd, A. K. H. MacGibbon, and R. G. Snell. 2014. Estimation of genetic and crossbreeding parameters of fatty acid concentrations in milk fat predicted by mid-infrared spectroscopy in New Zealand dairy cattle. J. Dairy Res. 81:340-349. https: //doi.org/10.1017/S0022029914000272.

MacGibbon, A. K. H. 1996. Herd-to-herd variations in the properties of milkfat. Proc. N.Z. Soc. Anim. Prod. 56:224-227.

MacGibbon, A. K. H., and W. D. McLennan. 1987. Hardness of New Zealand patted butter: Seasonal and regional variations. N. Z. J. Dairy Sci. Technol. 22:143-156.
MacGibbon, A. K. H., and M. M. Taylor. 2006. Composition and structure of bovine milk lipids. Pages 1-42 in Advanced Dairy Chemistry. Vol. 2. Lipids. P. F. Fox and P. L. H. McSweeney, ed. Springer, New York, NY.

Maijala, K. 2000. Cow milk and human development and well-being. Livest. Prod. Sci. 65:1-18. https://doi.org/10.1016/S0301 -6226(00)00194-9.

Manuelian, C. L., M. Penasa, G. Visentin, A. Benedet, M. Cassandro, and M. De Marchi. 2019. Multi-breed herd approach to detect breed differences in composition and fatty acid profile of cow milk. Czech J. Anim. Sci. 64:11-16. https://doi.org/10.17221/18/2018 -CJAS.

Mele, M., R. Dal Zotto, M. Cassandro, G. Conte, A. Serra, A. Buccioni, G. Bittante, and P. Secchiari. 2009. Genetic parameters for conjugated linoleic acid, selected milk fatty acids, and milk fatty acid unsaturation of Italian Holstein-Friesian cows. J. Dairy Sci. 92:392-400. https://doi.org/10.3168/jds.2008-1445.

Nafikov, R. A., H. Soyeurt, and D. C. Beitz. 2015. Genetics of fatty acid composition in bovine milk and beef. Pages 433-450 in The Genetics of Cattle. D. J. Garrick and A. Ruvinsky, ed. CAB International, Wallingford, UK.

Narayana, S. G., F. S. Schenkel, A. Fleming, A. Koeck, F. Malchiodi, J. Jamrozik, J. Johnston, M. Sargolzaei, and F. Miglior. 2017. Genetic analysis of groups of mid-infrared predicted fatty acids in milk. J. Dairy Sci. 100:4731-4744. https://doi.org/10.3168/jds .2016-12244.

Niero, G., G. Visentin, S. Ton, M. De Marchi, M. Penasa, and M. Cassandro. 2016. Phenotypic characterisation of milk technological traits, protein fractions, and major mineral and fatty acid composition of Burlina cattle breed. Ital. J. Anim. Sci. 15:576-583. https: //doi.org/10.1080/1828051X.2016.1250128.

Palmquist, D. L., A. D. Beaulieu, and D. M. Barbano. 1993. Feed and animal factors influencing milk fat composition. J. Dairy Sci. 76:1753-1771. https://doi.org/10.3168/jds.S0022-0302(93)77508 -6 .

Pegolo, S., A. Cecchinato, J. Casellas, G. Conte, M. Mele, S. Schiavon, and G. Bittante. 2016. Genetic and environmental relationships of detailed milk fatty acids profile determined by gas chromatography in Brown Swiss cows. J. Dairy Sci. 99:1315-1330. https://doi .org/10.3168/jds.2015-9596.

Samková, E., J. Koubová, L. Hasonová, O. Hanuš, R. Kala, M. Kvác, T. Pelikánová, and J. Špicka. 2018. Joint effects of breed, parity, month of lactation, and cow individuality on the milk fatty acids composition. Mljekarstvo 68:98-107.

Schennink, A., W. M. Stoop, M. H. P. W. Visker, J. M. L. Heck, H. Bovenhuis, J. J. Van Der Poel, H. J. F. Van Valenberg, and J. A. M. Van Arendonk. 2007. DGAT1 underlies large genetic variation in milk-fat composition of dairy cows. Anim. Genet. 38:467-473. https://doi.org/10.1111/j.1365-2052.2007.01635.x.

Sneddon, N. W., N. Lopez-Villalobos, S. R. Davis, R. E. Hickson, and L. Shalloo. 2015. Genetic parameters for milk components including lactose from test day records in the New Zealand dairy herd. N. Z. J. Agric. Res. 58:97-107. https://doi.org/10.1080/00288233 2014.978482 .

Soyeurt, H., P. Dardenne, F. Dehareng, G. Lognay, D. Veselko, M. Marlier, C. Bertozzi, P. Mayeres, and N. Gengler. 2006a. Estimating fatty acid content in cow milk using mid-infrared spectrometry. J. Dairy Sci. 89:3690-3695. https://doi.org/10.3168/jds.S0022 -0302(06)72409-2.

Soyeurt, H., P. Dardenne, A. Gillon, C. Croquet, S. Vanderick, P. Mayeres, C. Bertozzi, and N. Gengler. 2006b. Variation in fatty acids contents of milk and milk fat within and across breeds. J. Dairy Sci. 89:4858-4865. https://doi.org/10.3168/jds.S0022 -0302(06)72534-6.

Soyeurt, H., A. Gillon, S. Vanderick, P. Mayeres, C. Bertozzi, and N. Gengler. 2007. Estimation of heritability and genetic correlations for the major fatty acids in bovine milk. J. Dairy Sci. 90:44354442. https://doi.org/10.3168/jds.2007-0054.

Spelman, R. J., F. M. Miller, J. D. Hooper, M. Thielen, and D. J. Garrick. 2001. Experimental design for QTL trail involving New 
Zealand Friesian and Jersey breeds. Proc. Assoc. Advmt. Anim. Breed. Genet. 14:393-396.

Stoop, W. M. 2009. Genetic variation in bovine milk fat composition. $\mathrm{PhD}$ thesis. Wageningen University, Wageningen, the Netherlands.

Stoop, W. M., J. A. M. Van Arendonk, J. M. L. Heck, H. J. F. Van Valenberg, and H. Bovenhuis. 2008. Genetic parameters for major milk fatty acids and milk production traits of Dutch HolsteinFriesians. J. Dairy Sci. 91:385-394. https://doi.org/10.3168/jds 2007-0181.

\section{ORCIDS}

N. Lopez-Villalobos @ https://orcid.org/0000-0001-6611-907X

S. R. Davis @ https://orcid.org/0000-0002-4942-1055

S. D. Berry (ํ) https://orcid.org/0000-0002-2352-9754

N. W. Sneddon ๑ https://orcid.org/0000-0001-9704-1287

A. K. MacGibbon () https://orcid.org/0000-0002-1223-3501 